\title{
SPONTANEOUS RUPTURE OF SPLEEN
}

\author{
Wg Cdr KL SAMPATH KUMAR*
}

MJAFI 1999; 55 : 255-256

KEY WORDS: Spleen; Spontaneous rupture.

\section{Introduction}

Though the rupture of spleen is seen in a larger hospital often, the aetiology in most of these cases is trauma. However, the spontaneous rupture of the spleen is rare in regular surgical practice of a smaller peripheral hospital.

\section{Case Report}

A 32-years-old male patient was brought to the hospital with the history of "Sudden Collapse" in the unit. On questioning the patient, he gave a history of low to moderate degree of fever for the last seven days prior to admission. He was taking symptomatic treatment in the form of antipyretics from the unit MI room. The investigations which were carried out in the unit MI room were reported to be normal. The peripheral blood smear for the malarial parasite was reported to be negative. In the hospital, the patient was conscious, responding to verbal commands relevantly. He had tachycardia of $110 / \mathrm{mt}$, hypotension of $80 \mathrm{~mm}$ of $\mathrm{Hg}$ of systolic blood pressure. The patient was pale. Examination of the abdomen revealed evidence of distension of the left half of the abdomen. There was tendemess as well as rigidity over left half of the abdomen. Clinically there was evidence of free fluid in the peritoneal cavity. Bowel sounds were normal. A per rectal examination revealed no abnormality. The finger stall was stained with normal faecal colour. Other systemic examination was within normal limits. Diagnostic peritoneal tap revealed the evidence of haemoperitoneum.

Plain radiograph of abdomen was done while preparing for exploratory laparotomy, which revealed ground glass appearance. Routine haemogram revealed anaemia (Hb:9 Gm/dl) with leucocytosis (TLC: $12600 / \mathrm{cmm}$ and Polymorphs of $78 \%$ ). Peripheral blood smear for Malarial parasite was negative. Urinalysis did not reveal any abnormality. Ultrasound examination of the abdomen could not be done on account of lack of facilities.

In view of the patient's clinical condition, the patient was taken up for immediate exploratory laparotomy. Laparotomy was done through the midline incision extending from xiphisternum to a point just below the umbicilus, skirting around the umbilicus. At laparotomy, haemoperitonieum was encountered. On evacuation of blood, it was revealed that there was rupture of spleen. Hence, the incision was extended on to the ieft hypochondrium as the left oblique subcostal incision. The spleen was delivered at the wound as rapidly as possible by passing a hand over the lateral surface of the spleen, between it and the diaphragm; the organ was lifted forwards and medially, and the posterior layer of the lienorenal ligament was divided under vision. A hot moist pack was placed behind it. Then the gastrosplenic ligament was divided. The combined pedicle-peritoneal and vascular was clamped and divided in small sections at a time, from below upwards. The clarnps were applied as close as possible to the hilum to obviate the risk of injury to the tail of pancreas. Haemostasis was ensured. Small fragments of the splenic tissue were picked up from the peritoneal cavity. Abdomen was closed over a corrugated rubber drain. The patient was given four units of compatible blood during the intraoperative and immediate postoperative period. Since the patient was located in north West Bengal, a known endemic area of chloroquine resistant falciparum malaria $[1,2]$, the patient was given anti malarial treatment in the form of Inj. Quinine in the postoperative period. Later on the histological examination of the spleen revealed the presence of malarial parasites (Plasmodium falciparum ) in the capillaries.

\section{Discussion}

The term "rupture" has been applied to splenic injuries in which there is disruption of the organ's parenchyma, capsule or blood supply [3].

The causes of splenic rupture include penetrating trauma, non penetrating or blunt trauma, operative trauma and rarely a spontaneous event $[4,5]$.

Although spontaneous rupture of the normal spleen has been reported in approximately two dozen cases [6], it is a much more common event when the spleen is involved with a haematological disorder.

In cases where the spleen is enlarged from disease notably malaria or kalazar especially in India, rupture may result from comparatively minor trauma.

It is likely that the majority of patients classified as experiencing spontaneous rupture had trauma that was not appreciated.

In this case, the patient denied any type of injury to the abdomen. As per the patient, on account of fever, he was excused to perform any duty and he was spending most of his time taking rest either sitting on a chair or lying on a cot. In fact, as there was no history of trauma, the patient was admitted in the medical ward and in view of fever and hypotension, peripheral circulatory failure secondary to infection was considered as the initial diagnosis.

However, during the course of illness 4-6 hrs after the hospitalisation, the tell-tale signs of haemoperi-

* Classified Specialist in Surgery, 9 Air Force Hospital, Halwara (AD) 141106. 
toneum were noticed and the patient was taken up for immediate surgery.

At laparotomy, the spleen was found to be enlarged to some extent. But, as expected in a case of spontaneous rupture of the spleen, there was no massive enlargement. The total weight of this ruptured spleen was found to be $450 \mathrm{gm}$ (approximately two times its normal weight). The spleen was soft and there was a single tear involving splenic parenchyma passing through the hilar region and the capsule. Hence splenectomy performed rather than splenorraphy $[7,8]$.

\section{REFERENCES}

1. The Clinical management of acute malaria. WHO Regional publications, South East Asia Series 1986;9:33-87.

2. WHO Division of control of tropical disease. Trans Royal Society of Tropical Medicine Hygiene 1990: 84 (supplemen- tary): $1-65$.

3. Schwartz SI. Spleen In: Schwartz SI, Tom Shires G, Spencer FC, Editors. Principles of Surgery. 5th ed. New; Mc GrawHill Book company 1988;1441-6.

4. Sargison KD, Cole TP, Kyle J. Traumatic rupture of the spleen. Br J Surg 1968 55:506.

5. Orloff MJ, Perkin GW. Collective review-Spontaneous rupture of the normal spleen: A surgical enigma. Internal Abstract Surgery 106;1: 1958.

6. Schwartz SI. Spleen In: Schwarz SI, Harold Ellis, editors. Maingot's Abdominal operations. 8th ed. Norwalk; Appleton-Century-Crofts 1985:2253-66.

7. King DR, Lobe TE, et al. Selective management of injured spleen. Surgery 1981;90: 677.

8. Traetow WD, Fabri PJ, Carley LC. Changing indications for splenectomy; 30 years experience. Archives of Surgery 1980;115:447. 